\title{
CRESCIMENTO RELATIVO E MATURIDADE SEXUAL MORFOLÓGICA DO CAMARÃO DE ÁGUA DOCE MACROBRACHIUM IHERINGI (CARIDEA, PALAEMONIDAE), NO RIBEIRÃO HORTELÃ, BOTUCATU, SP, BRASIL
}

\author{
Nogueira, C.S. ${ }^{1,}$; Perroca, J.F. ${ }^{1}$; Piantkoski, E.L. ${ }^{1}$; Costa, R.C. ${ }^{1}$; Taddei, F.G. ${ }^{2}$ \& Fransozo, A. ${ }^{3}$ \\ ${ }^{1}$ Universidade Estadual Paulista "Júlio de Mesquita Filho" (UNESP), Campus Bauru, Laboratório de Biologia de \\ Camarões Marinhos e de Água Doce. \\ ${ }^{2}$ Universidade do Estado do Amazonas (UEA), Centro de Estudos Superiores de Parintins, Laboratório de Estudos de \\ Crustáceos da Amazônia. \\ ${ }^{3}$ Universidade Estadual Paulista "Júlio de Mesquita Filho" (UNESP), Campus Botucatu, Núcleo de Estudos em \\ Biologia, Ecologia e Cultivo de Crustáceos.
}

*Autor correspondente: caiosnogueira@hotmail.com

\begin{abstract}
Durante o desenvolvimento ontogenético dos crustáceos, o crescimento de algumas estruturas pode se intensificar, principalmente na passagem da fase jovem para a adulta, e estas diferenças podem ser classificadas a partir do método da análise do crescimento relativo. Esse estudo teve como objetivo, estimar o comprimento de carapaça no qual esses animais alcançam a maturidade sexual morfológica e descrever as variações proporcionais no crescimento em Macrobrachium iheringi. Amostras de M. iheringi foram coletadas mensalmente entre julho/1991 a junho/1992 e julho/1993 a junho/1994, no "Ribeirão da Hortelã", situado em Botucatu-SP. No período diurno, por 90 minutos, dois coletores usaram peneiras próximo à margem do rio, abrangendo um transecto de $200 \mathrm{~m}$. Com o auxílio de um paquímetro digital $(0.01 \mathrm{~mm})$, o comprimento das estruturas: carapaça (CC), abdome $(A B)$, ísquio $(C I)$, mero $(C M)$, carpo $(C A)$, própodo $(C P)$ e dáctilo $(C D)$, a largura da segunda pleura abdominal (LP) e altura do própodo (AP) foram mensuradas e incluídas nas análises. Um total de 368 indivíduos foram analisados, esses sendo 171 machos e 197 fêmeas. Os valores de medidas referentes aos artículos foram obtidos a partir da mensuração do segundo pereiópodo direito. As relações que melhor demonstraram as alterações no coeficiente alométrico entre os sexos, foram: para fêmeas, CC vs LP e, para machos CC vs CP. Todas as relações morfométricas referente ao quelípodo diferiram entre os adultos e jovens de ambos os sexos, sendo maioria o desenvolvimento isométrico em fêmeas e alométrico nos machos. Quanto as relações morfométricas referentes ao $\mathrm{AB}$ e $\mathrm{LP}$, o desenvolvimento da pleura diferiu entre jovens e adultos de ambos os sexos, porém, o desenvolvimento do abdômen nos machos mostrou possuir o mesmo padrão de desenvolvimento, enquanto nas fêmeas houve diferenciação. O CC em que fêmeas e machos a atingem maturidade sexual morfológica foi estimado em $11.1 \mathrm{~mm}$ e $13.3 \mathrm{~mm}$, respectivamente. Os machos apresentaram tamanho médio de 10.78 $\pm 3.78 \mathrm{~mm}$ CC, enquanto que as fêmeas $9.22 \pm 3.53 \mathrm{~mm}$ CC. Assim, é possível visualizarmos que estruturas como o própodo do segundo pereiópodo e pleura são bons indicadores para estimar a maturidade sexual morfológica dessa espécie, como também já relatado para outras espécies do gênero Macrobrachium, uma vez que, o própodo é utilizado pelos machos em interações agonísticas associadas com a reprodução e, a largura da pleura, utilizada no transporte e armazenamento dos ovos.
\end{abstract}

Palavras-chave: alometria, dimorfismo sexual, morfometria, reprodução. 